Article

\title{
Applying SBM-GPA Model to Explore Urban Land Use Efficiency Considering Ecological Development in China
}

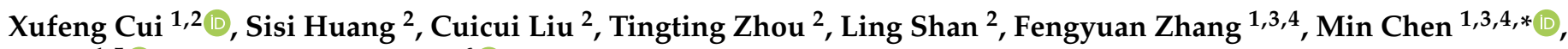 \\ Fei $\mathrm{Li}^{1,5}$ and Walter $\mathrm{T}$. de Vries ${ }^{6}$
}

1 Key Laboratory of Virtual Geographic Environment (Ministry of Education of PRC), Nanjing Normal University, Nanjing 210046, China; cxf@zuel.edu.cn (X.C.); zhangfengyuan@njnu.edu.cn (F.Z.); lifei@zuel.edu.cn (F.L.)

2 School of Business Administration, Zhongnan University of Economics and Law, Wuhan 430073, China; hss@stu.zuel.edu.cn (S.H.); lcc@stu.zuel.edu.cn (C.L.); ztt@stu.zuel.edu.cn (T.Z.); shanling@stu.zuel.edu.cn (L.S.)

3 Jiangsu Center for Collaborative Innovation in Geographical Information Resource Development and Application, Nanjing Normal University, Nanjing 210023, China

4 State Key Laboratory Cultivation Base of Geographical Environment Evolution (Jiangsu Province), Nanjing Normal University, Nanjing 210023, China

5 School of Information and Safety Engineering, Zhongnan University of Economics and Law, Wuhan 430073, China

6 Department of Aerospace and Geodesy, Technical University of Munich (TUM), 80333 München, Germany; wt.de-vries@tum.de

* Correspondence: chenmin0902@njnu.edu.cn

Citation: Cui, X.; Huang, S.; Liu, C.; Zhou, T.; Shan, L.; Zhang, F; Chen, M.; Li, F.; de Vries, W.T. Applying SBM-GPA Model to Explore Urban Land Use Efficiency Considering Ecological Development in China. Land 2021, 10, 912. https://doi.org/ 10.3390/land10090912

Academic Editor: Zahra Kalantari

Received: 24 June 2021

Accepted: 25 August 2021

Published: 28 August 2021

Publisher's Note: MDPI stays neutral with regard to jurisdictional claims in published maps and institutional affiliations.

Copyright: () 2021 by the authors. Licensee MDPI, Basel, Switzerland. This article is an open access article distributed under the terms and conditions of the Creative Commons Attribution (CC BY) license (https:// creativecommons.org/licenses/by/ $4.0 /)$.

\begin{abstract}
Rapid urban sprawl is a key characteristic of the current urban land use changes in China. It leads, however, to inefficient land use and spatial imbalance. This paper conducts a quantitative analysis of the urban land use efficiency (ULUE) at a provincial scale in China, based on the SBM-GPA integration model, and using the datasets of 31 province-level regions (provinces, municipalities and autonomous regions) in Chinese mainland from 2008 to 2017. The analysis demonstrates that: (1) the proportion of provinces reaching the production frontiers is low, but there are possibilities to improve for the ULUE; (2) the provincial ULUE strongly correlates to the type of agglomeration characteristics, and the degree of agglomeration tends to increase year by year; (3) there are three types of clusters of provincial ULUE values: high, medium, and low; (4) the gravity center of the provincial ULUE is located in Henan Province, where values are relatively stable and limited changes occur. The novelty of this research is that it applies spatial modeling to characterize and analyze ULUE spatial and temporal variations and clusters in China. Practically, this can better support decision making in urban land use management.
\end{abstract}

Keywords: urban land use efficiency; geospatial analysis methods (GPA); slacks-based measure model (SBM); China

\section{Introduction}

Urban land is the spatial carrier of urban economy, society, and environment [1], and urban land use efficiency (ULUE) plays an important role in sustainable city development $[2,3]$. In recent years, China has implemented different types of land use policies to enhance urban land use efficiency, such as the "Increasing Deposit linkage of urban and rural construction land" ("ZengJianGuaGou" in Chinese) (Ministry of Land and Resources of PRC, 2004), "Guiding on intensive land use" (Ministry of Land and Resources of PRC, 2014), "Provisions for economical and intensive use of land" (Ministry of Land and Resources of PRC, 2014), "Monitoring of intensive land use" (Ministry of Natural Resources of PRC, 2020), etc. The implementation of these policies promoted the land use efficiency significantly. 
Despite these acknowledged improvements to date, a further improvement of the ULUE is still critical. One of the reasons is that since the reform of the tax sharing system in China, local governments tend to opt for policies that increase the volume of real estate projects in a largely uncontrolled and unlimited manner [4]. The impacts of these include a continued rapid urban expansion [5] and a less efficient land use [6,7]. Moreover, it causes land use fragmentation and disorderly urban development, unmanaged idle land and environmental degradation [8]. Such developments restrict the social and economic development of cities, because of the decreasing availability of land and inefficient use [9]. Hence, there is a need for the more effective use of land, which will be better able to alleviate the contradiction between population growth and limited land supply, and ultimately achieve sustainable land use [10,11]. Yet, given the current status quo of increasing population numbers and decreasing land availability in China, improvement in the ULUE is not evident. It is a complex quandary which necessitates a better understanding of spatial and temporal connections and a better insight into the effectiveness of land policy interventions [12]. This article addresses this research problem. It investigates how efficient current urban land use is in provinces in China from the perspective of input and output. From the analysis, we infer land policy recommendations.

This study employs the slacks-based measure model (SBM) to measure the degree and variation of the land use efficiency of 31 province-level regions (include provinces, municipalities and autonomous regions) in Chinese mainland between 2008 and 2017. The characteristics of the spatial distribution of ULUE are identified using geospatial analysis methods (GPA) combining GeoDa1.14 and GIS methods [13-16]. The findings of this research support the development of sustainable urban land use and provide a quantitative informed basis for government decision making.

This article starts by explaining current notions on spatial expansion, alongside introducing the research trends and problems related to ULUE. The subsequent section synthesizes the current popular methods and frameworks for measuring ULUE. The third part introduces the freely available panel data and the SBM model. The next part describes how to use the spatial analysis tools to analyze the efficiency of the data, and presents the index data and model results. Finally, this article synthesizes the findings, putting forward the corresponding conclusions and suggestions of land policy according to the data results.

\section{Current State of the Art on Describing and Measuring ULUE}

There are different approaches to describe, measure and analyze ULUE. Research on ULUE relates to its evaluation $[2,4,17]$, space-time characteristics $[12,18,19]$, influencing factors [20] of ULUE, and ways to improve ULUE [21-23]. Research methods are also increasingly diversified, mainly including the coupling degree model [24], the CobbDouglas production function [25], data envelopment analysis [26], stochastic frontier analysis [27], the directional distance function [28], Theil index [29], Gini coefficient [19], and so on (Table 1). The technological framework has evolved from a single indicator framework reflecting the economic benefits of urban land use [30] to a multi-indicator framework reflecting economic, social and ecological development [31]. The research scale includes the country level [18,32], economic belts [33,34], urban agglomerations [35], and typical cities $[22,36]$.

The existing research on ULUE has been relatively rich, but the research on spatial characteristics is a little insufficient, and needs to be further explored. In this study, we apply the SBM-GPA model to evaluate ULUE considering land ecological development, identify its spatial pattern and track its gravity shift. The integration of the SBM-GPA model enables us to solve problems more comprehensively and effectively. 
Table 1. Methods of ULUE.

\begin{tabular}{|c|c|c|c|}
\hline Methods & Advantages & Disadvantages & Sources \\
\hline Coupling Degree Model & $\begin{array}{l}\text { Reflects the harmonious degree and benign } \\
\text { coordination relationship of } \\
\text { system components. }\end{array}$ & $\begin{array}{l}\text { Only reflects the relationship between } \\
\text { elements; cannot reflect the internal } \\
\text { relationship of elements. }\end{array}$ & [24] \\
\hline $\begin{array}{l}\text { Cobb-Douglas } \\
\text { Production Function }\end{array}$ & $\begin{array}{l}\text { Effectively analyzes the impact of input on } \\
\text { output and explores the relationship between } \\
\text { the number of various production factors. }\end{array}$ & $\begin{array}{l}\text { Cannot distinguish the difference } \\
\text { between input factors, and the } \\
\text { calculated results may not be consistent } \\
\text { with the actual situation. }\end{array}$ & [25] \\
\hline $\begin{array}{l}\text { Data Envelopment } \\
\text { Analysis (DEA) }\end{array}$ & $\begin{array}{l}\text { A popular non-parametric method for } \\
\text { evaluating the relative efficiency of } \\
\text { decision-making units (DMUs) with multiple } \\
\text { inputs and outputs. }\end{array}$ & $\begin{array}{l}\text { Lacks input-output relaxation variables } \\
\text { and neglects data measurement errors. }\end{array}$ & [26] \\
\hline $\begin{array}{l}\text { Stochastic Frontier } \\
\text { Analysis (SFA) }\end{array}$ & $\begin{array}{l}\text { A popular parametric method for considering } \\
\text { the influence of random factors on output. }\end{array}$ & $\begin{array}{l}\text { Cannot be used for multiple outputs, } \\
\text { but can only be used for a } \\
\text { single output. }\end{array}$ & [27] \\
\hline $\begin{array}{l}\text { Directional Distance } \\
\text { Function (DDF) }\end{array}$ & $\begin{array}{l}\text { Widely used to process efficiency evaluation } \\
\text { and obtains unbiased dynamic efficiency } \\
\text { evaluation results. }\end{array}$ & $\begin{array}{l}\text { Lacks theoretical basis and does not } \\
\text { discuss the choice of direction. }\end{array}$ & [28] \\
\hline Theil Index & $\begin{array}{l}\text { Reflects the overall difference and reveals the } \\
\text { source of regional difference. }\end{array}$ & $\begin{array}{l}\text { Does not consider how subsamples } \\
\text { within a subpopulation are distributed. }\end{array}$ & [29] \\
\hline Gini Coefficient & $\begin{array}{l}\text { Quantitatively describes the characteristics of } \\
\text { spatial differences and reveals the composition } \\
\text { and source of spatial differences. }\end{array}$ & $\begin{array}{l}\text { Reflects a general time point change, } \\
\text { and cannot reflect the overall change } \\
\text { process and situation. }\end{array}$ & [19] \\
\hline
\end{tabular}

\section{Data and Methods}

\subsection{Data}

Panel data of 31 province-level regions in China of 2008-2017 (excluding Hong Kong, Macao, Taiwan) were employed to analyze the degree and variation of ULUE (Figure 1). These data provide information on fixed asset investments, the area of construction land areas, employees in the secondary and tertiary industries, the added value of the secondary and tertiary industries, per capita disposable income of urban residents, the greenery coverage of urban area, and industrial sulfur dioxide emissions, etc. The fixed asset investment is expressed in the form of currency, and the total amount of work and expenses are related to the construction and purchase of fixed assets by the whole society in a certain period of time. All these data are part of the China Statistics Yearbook (National Bureau of Statistics of China, 2009-2018), which is openly accessible and can be used freely.

\subsection{Methods}

This study employed the integrated method named SBM-GPA (Figure 2) to evaluate and analyze the ULUE in China. The input parameters were categories of urban land input indicators and output indicators (including expected output and undesired output indicators). The GPA model undertook the spatial statistical analysis of technical efficiency, pure technical efficiency, and scale efficiency. Technical efficiency (TE) can be decomposed into pure technical efficiency (PTE) and scale efficiency (SE), TE $=$ PTE $\times$ SE and TE is equal to 1 only if both PTE and SE are equal to 1, which means that this index is efficient. PTE reflects the production efficiency of input factors at the optimal scale of decisionmaking unit, and SE reflects the difference between the actual scale and the optimal production scale.

The GPA model includes 2 sub-models: the spatial autocorrelation model and center of gravity analysis model. The spatial autocorrelation model identifies global and local spatial distribution patterns; it is calculated by the Global Moran Index. Calculating global spatial distribution patterns can rely on a clustering mode, discrete mode or random mode. The center of gravity analysis model can return the changing trend of the spatial distribution. The SBM-GPA integrated model can identity and visualize spatial patterns and spatial 
trends of urban land efficiency. Specifically, the SBM model can measure the ULUE value of different provinces, whereas the GPA model is used to identify spatial characters of ULUE.
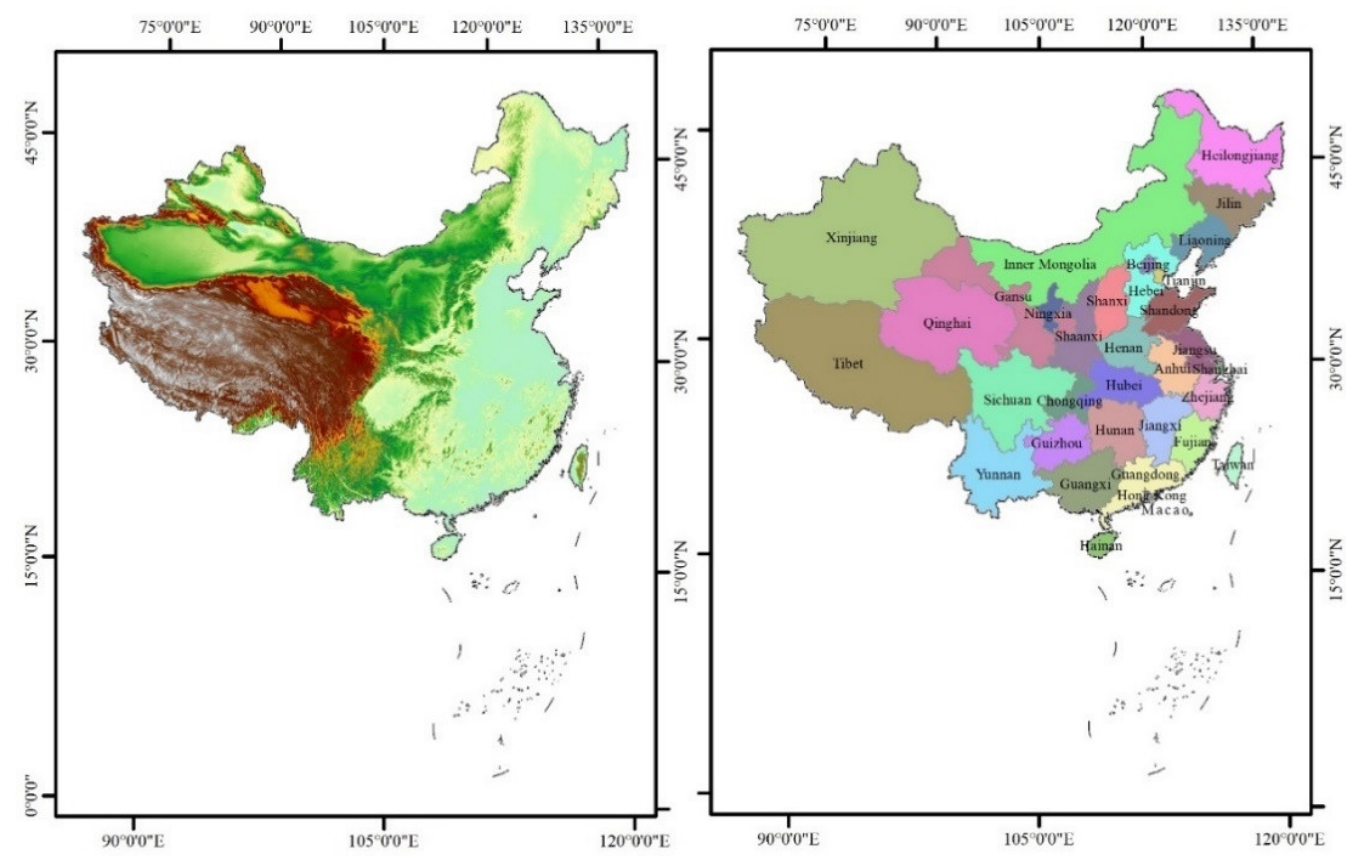

Figure 1. Location of study area in China.

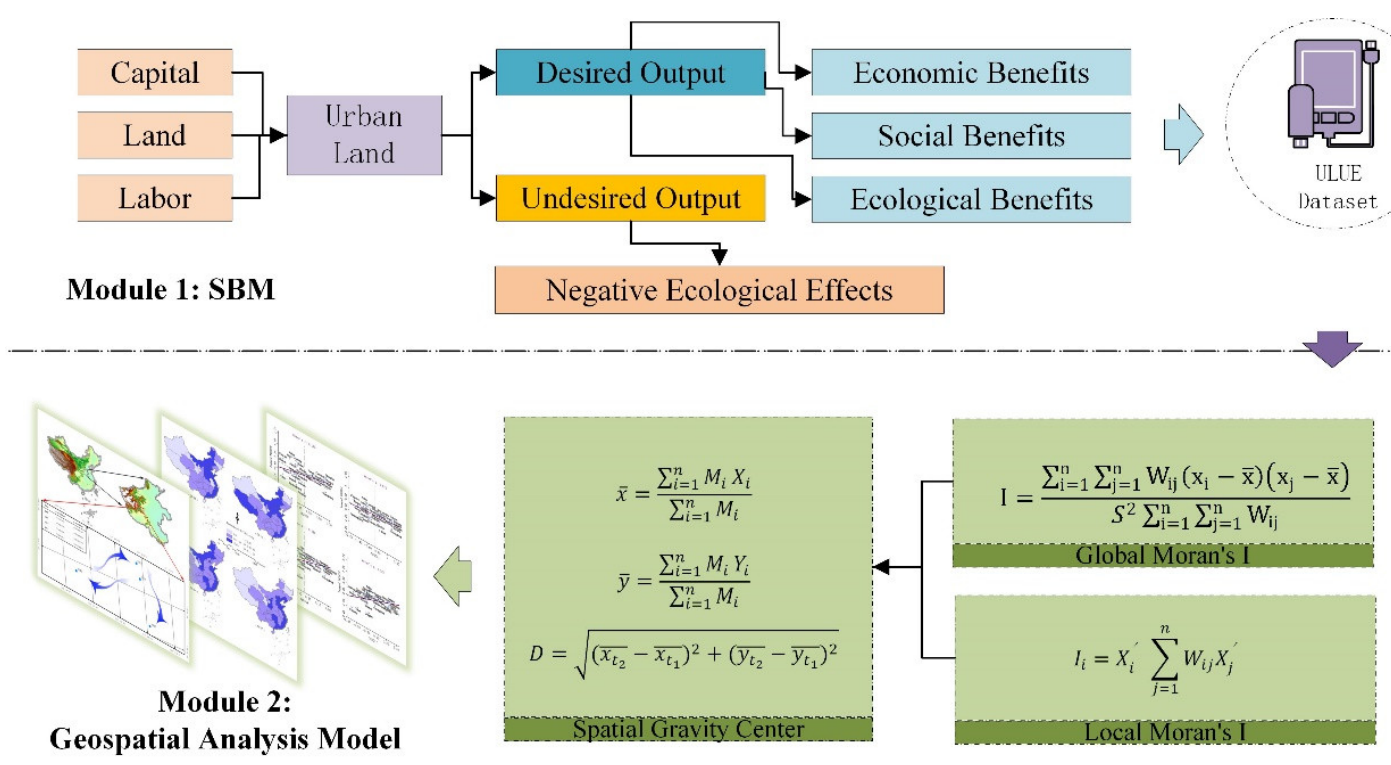

Figure 2. The structure of SBM-GPA model.

\subsubsection{SBM Model}

Data envelopment analysis (DEA) is a multi-input and multi-output analysis method [37], that is, a systematic analysis method for evaluating the relative efficiency between factor inputs and outputs [38]. There are many advantages of this method, as there is no need to determine the functional relationship in advance, it has non-subjective weighting, and analyzing invalid factors of decision units is feasible. Therefore, DEA has become a mainstream technical tool for evaluating relative efficiency. Hence, we employed the slacks-based measure (SBM) model in non-radial DEA to solve the problem of efficiency evaluation when the units of input or output variables are inconsistent [35], that is, the output can be maximized under certain circumstances. 
The method can be explained as follows. Suppose there are $n$ decision-making units (DMUs) with $m$ input indicators, $S_{1}$ desirable outputs indicators and $S_{2}$ undesirable outputs indicators. Each DMU has three input and output vectors, expressed as $X, Y^{g}, Y^{b}$. They are defined as follows:

$$
\begin{gathered}
X=\left(x_{1}, x_{2}, \ldots, x_{n}\right) \in R^{m \times n}\left(x \in R_{m}\right) \\
Y^{g}=\left(y_{1}^{g}, y_{2}^{g}, \ldots, y_{n}^{g}\right) \in R^{S_{1} \times n}\left(y^{g} \in R^{S_{1}}\right) \\
Y^{b}=\left(y_{1}^{b}, y_{2}^{b}, \ldots, y_{n}^{b}\right) \in R^{S_{2} \times n}\left(y^{b} \in R^{S_{2}}\right)
\end{gathered}
$$

According to the actual situation of input and output, $X>0, Y^{g}>0, Y^{b}>0$, and the model can be defined as follows:

$$
\begin{gathered}
\rho^{*}=\min \frac{1-\frac{1}{m} \sum_{i=1}^{m} \frac{S_{i}^{-}}{X_{i 0}}}{1+\frac{1}{S_{1}+S_{2}}\left(\sum_{r=1}^{S_{1}} \frac{S_{r}^{g}}{y_{r 0}^{g}}+\sum_{r=1}^{S_{2}} \frac{S_{r}^{b}}{y_{r 0}^{b}}\right)},\left(0 \ll \rho^{*} \ll 1\right) \\
\text { s.t. }\left\{\begin{array}{c}
x_{0}=X \lambda+S^{-} \\
y_{0}^{g}=Y^{g} \lambda-S^{g} \\
y_{0}^{b}=Y^{b} \lambda+S^{b} \\
S^{-} \geq 0, S^{g} \geq 0, S^{b} \geq 0, \lambda \geq 0
\end{array}\right.
\end{gathered}
$$

$S_{i}^{-}, S_{r}^{g}, S_{r}^{b}$ denote the slack variables of input, desired output, and undesired output, respectively. When $\rho^{*}=1$, the DMU is on the perfect, efficient position on the production possibility curve. When $\rho^{*}<1$, the DMU is inefficient.

According to the existing literature, an evaluation framework for assessing urban land use efficiency is formed based on Chinese land use processes, considering the form of

\begin{tabular}{|c|c|c|c|c|}
\hline \multicolumn{3}{|c|}{ Criteria Layer } & Indicator Layer & Reference \\
\hline \multirow{3}{*}{$\begin{array}{l}\text { Input } \\
\text { indicators }\end{array}$} & \multicolumn{2}{|c|}{ Capital investment } & Fixed asset investment. & [39] \\
\hline & \multicolumn{2}{|c|}{ Land investment } & Areas of urban land. & {$[40,41]$} \\
\hline & \multicolumn{2}{|c|}{ Labor input } & $\begin{array}{c}\text { Employees in the secondary and tertiary } \\
\text { industries. }\end{array}$ & {$[40,41]$} \\
\hline \multirow{4}{*}{$\begin{array}{l}\text { Output } \\
\text { indicators }\end{array}$} & \multirow{3}{*}{ Desired output } & Economic benefits & $\begin{array}{l}\text { Added value of the secondary and tertiary } \\
\text { industries. }\end{array}$ & {$[19,41-43]$} \\
\hline & & Social benefits & $\begin{array}{l}\text { Annual per capita disposable income of } \\
\text { urban households. }\end{array}$ & [35] \\
\hline & & Ecological benefits & Green coverage within built-up area. & {$[33,39,41]$} \\
\hline & Undesired output & $\begin{array}{l}\text { Negative ecological } \\
\text { effects }\end{array}$ & Industrial sulfur dioxide emissions. & {$[35,40,42]$} \\
\hline
\end{tabular}
expected output and undesired output. Capital, land, and labor are set as input parameters, while economic, social and ecological benefits are set as the desired output, negative and ecological effects as the undesired output (Table 2).

Table 2. Quantitative evaluation index system for urban land use efficiency.

In terms of input indicators, the fixed asset investment means the total consumption of newly increased and depreciating fixed assets in a certain period of time, indicating the comprehensive capital investment in urban land. As the carrier of economic and social activities in the city, areas of urban land represent the input of land resources. The secondary and tertiary industries are the main industrial types in urban land use, so the number of employees in those indicates the input of labor resources for the use of urban land. 
In terms of output indicators, the secondary and tertiary industries are the main industries in urban land, so their added value can be used as an economic output indicator. The annual per capita disposable income of urban households can be used to measure the income and living standards of urban residents effectively, so it can also be used as an indicator of social benefits of land use. The green coverage within a built-up area is closely related to the good ecological environment and living conditions required for sustainable urban development, as an indicator of the ecological benefits of land use resources. Finally, the industrial $\mathrm{SO}_{2}$ emissions can be directly used to indicate the negative externalities that land use has on the environment.

\subsubsection{Geospatial Analysis Methods Spatial Autocorrelation Model}

Because of the spillover effect and diffusion effect of urban land use efficiency [44], it usually shows spatial characteristics, which can be quantified by a spatial autocorrelation model [45]. Such a spatial autocorrelation model can be divided into a global autocorrelation model and a local autocorrelation model. The global spatial autocorrelation model can determine the distribution patterns of the research object: clustering, discrete or random. Global Moran's I [46] is often used for this calculation, so we used it to calculate the spatial pattern of urban land use efficiency. The mathematical formula for the Global Moran Index is as follows $[47,48]$ :

$$
\mathrm{I}=\frac{\sum_{i=1}^{n} \sum_{j=1}^{n} W_{i j}\left(x_{i}-\bar{x}\right)\left(x_{j}-\bar{x}\right)}{S^{2} \sum_{i=1}^{n} \sum_{j=1}^{n} W_{i j}}, \mathrm{I} \in[-1,1]
$$

Among them, $x_{i}$ and $x_{j}$ are the observed values of urban land use efficiency in $i$ th area and $j$ th area, respectively. $W_{i j}$ is the corresponding element of the space weight matrix, $\mathrm{n}$ is the number of samples, and $\bar{x}$ is the mean value of ULUE while $S^{2}$ is the variance value. When $i$ th and $j$ th are adjacent to each other, the weight is 1 ; otherwise, the weight is 0 . The Global Moran's I is between a range of $[-1,1]$; the closer it is to -1 , the larger the difference between the units, and the more dispersed the distribution. The closer it is to +1 , the more similar the properties between units, and the closer the relationship. If the index is close to 0 , this indicates no correlation between units.

Local spatial autocorrelation can reflect the degree of spatial agglomeration of similar attribute values around a certain area and makes up for the lack of specific location in global spatial autocorrelation analysis. Local spatial autocorrelation is generally measured using Local Moran's I, and its mathematical formula is as follows [49]:

$$
\left\{\begin{array}{c}
I_{i}=X_{i}^{\prime} \times \sum_{j=1}^{n} W_{i j} \times X_{j}^{\prime} \\
X_{i}^{\prime}=\left(x_{i}-\bar{x}\right) / \frac{1}{n} \sum_{i=1}^{n}\left(x_{i}-\bar{x}\right)^{2} \\
X_{j}^{\prime}=\left(x_{j}-\bar{x}\right) / \frac{1}{n} \sum_{j=1}^{n}\left(x_{j}-\bar{x}\right)^{2}
\end{array}\right.
$$

Among them, $X_{i}^{\prime}$ and $X_{j}^{\prime}$ are the standardized observations of the ULUE in $i$ th area and $j$ th area, respectively. The meaning of the remaining variables is similar to that mentioned earlier and the test method is the same as the Global Moran's I.

\section{Spatial Gravity Center Model}

With the concept of the spatial gravity center, it is possible to calculate and analyze the spatial changes of provincial ULUE. The spatial gravity center model can calculate both the changing direction and distance $[35,50]$. 
If a study area consists of $\mathrm{n}$ spatial units and $\left(X_{i}, Y_{i}\right)$ are the geometric coordinates of the $i$ th unit $(i=1,2,3, \ldots, n)$, the gravity center coordinate yields as follows:

$$
\begin{gathered}
\bar{x}=\frac{\sum_{i=1}^{n} M_{i} X_{i}}{\sum_{i=1}^{n} M_{i}} \\
\bar{y}=\frac{\sum_{i=1}^{n} M_{i} Y_{i}}{\sum_{i=1}^{n} M_{i}}
\end{gathered}
$$

Among them, $(\bar{x}, \bar{y})$ represent the gravity center coordinates of the provincial urban land use efficiency, and $M_{i}$ refers to the attribute value of the $i$ th unit. The moving direction of the gravity center is as follows:

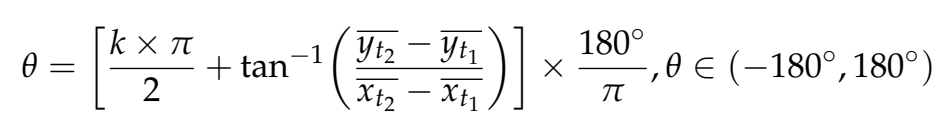

Among them, $\theta$ refers to the deviation angle of the gravity center during the study period, $\left(\overline{x_{t_{1}}}, \overline{y_{t_{1}}}\right)$ and $\left(\overline{x_{t_{2}}}, \overline{y_{t_{2}}}\right)$ represent the gravity center coordinate at the beginning and end of our study, respectively, $t_{1}$ and $t_{2}$ refer to the beginning and end of study period, respectively, $k$ represents the adjustment coefficient and $k=0,1$ and 2 .

The moving distance of the gravity center is as follows:

$$
D=\sqrt{\left(\overline{x_{t_{2}}}-\overline{x_{t_{1}}}\right)^{2}+\left(\overline{y_{t_{2}}}-\overline{y_{t_{1}}}\right)^{2}}
$$

Among them, $D$ represents the moving distance of the gravity center during the study period, $\left(\overline{x_{t_{1}}}, \overline{y_{t_{1}}}\right)$ and $\left(\overline{x_{t_{2}}}, \overline{y_{t_{2}}}\right)$ represent the gravity center coordinate at the beginning and end of the study, respectively, and $t_{1}$ and $t_{2}$ refer to the beginning and end of study period, respectively [51].

\section{Results}

\subsection{Evaluation of Provincial Urban Land Use Efficiency}

This study applied R language and algorithms to calculate the technical efficiency (TE) of the 31 province-level regions (provinces, municipalities and autonomous regions) in Chinese mainland on time nodes of 2008, 2011, 2014, and 2017 (Table 3). Technical efficiency (TE) can be decomposed into pure technical efficiency (PTE) and scale efficiency (SE), TE = PTE $\times$ SE and TE is equal to 1 only if both PTE and SE are equal to 1, which means that this index is efficient. PTE reflects the production efficiency of input factors at the optimal scale of decision-making unit, and SE reflects the difference between the actual scale and the optimal production scale.

According to the analysis of the production frontier of land use efficiency, in 2008, Shanghai, Jiangsu, Zhejiang, Fujian, and Guangdong had a pure technical efficiency and scale efficiency of 1 . In the remaining 26 provinces (Table 3 ), the pure technical efficiency and scale efficiency were both less than 1 , which is at the non-production frontier of land use efficiency. There is space for improvement in pure technical efficiency and scale efficiency. In 2011, only the six provinces of Tianjin, Shanghai, Jiangsu, Zhejiang, Guangdong, and Shaanxi had a pure technical efficiency and scale efficiency of 1 , which were at the forefront of generation and had technological effectiveness. The remaining provinces had not yet reached the frontier of generation, and there was space for efficiency improvement. In 2014, for Beijing, Tianjin, Inner Mongolia, Shanghai, and Guangdong, the pure technical efficiency and scale efficiency of the five provinces were all 1 , reaching the frontier of production. The remaining 27 provinces had not yet reached the frontier of production, and there was hence room for efficiency improvement. In 2017, only the four provinces of Beijing, Tianjin, Shanghai, and Fujian had a pure technical efficiency and scale efficiency of 1 , implying that these were at the forefront of production land use efficiency production. 
Table 3. Decomposition of provincial urban land use efficiency in China.

\begin{tabular}{|c|c|c|c|c|c|c|c|c|c|c|c|c|}
\hline \multirow{2}{*}{ Province } & \multicolumn{3}{|c|}{2008} & \multicolumn{3}{|c|}{2011} & \multicolumn{3}{|c|}{2014} & \multicolumn{3}{|c|}{2017} \\
\hline & TE & PTE & SE & TE & PTE & SE & TE & PTE & SE & TE & PTE & SE \\
\hline Beijing & 0.9107 & 0.9291 & 0.9802 & 0.9651 & 0.9937 & 0.9713 & 1.0000 & 1.0000 & 1.0000 & 1.0000 & 1.0000 & 1.0000 \\
\hline Tianjin & 0.9774 & 1.0000 & 0.9774 & 1.0000 & 1.0000 & 1.0000 & 1.0000 & 1.0000 & 1.0000 & 1.0000 & 1.0000 & 1.0000 \\
\hline Hebei & 0.9638 & 0.9651 & 0.9987 & 0.8844 & 0.9587 & 0.9225 & 0.7656 & 0.3950 & 1.9381 & 0.8460 & 0.9485 & 0.8920 \\
\hline Shanxi & 0.8579 & 0.8752 & 0.9802 & 0.8261 & 0.8285 & 0.9972 & 0.6172 & 0.4137 & 1.4919 & 0.7618 & 0.7800 & 0.9766 \\
\hline Inner Mongolia & 0.8137 & 0.8296 & 0.9808 & 0.8765 & 0.9102 & 0.9630 & 1.0000 & 1.0000 & 1.0000 & 0.7549 & 0.7614 & 0.9915 \\
\hline Liaoning & 0.6315 & 0.6340 & 0.9960 & 0.6716 & 0.6756 & 0.9941 & 0.7526 & 0.5164 & 1.4574 & 0.8417 & 0.8492 & 0.9912 \\
\hline Jilin & 0.5541 & 0.5679 & 0.9758 & 0.6463 & 0.6633 & 0.9743 & 0.7131 & 0.3262 & 2.1861 & 0.6612 & 0.6791 & 0.9736 \\
\hline Heilongjiang & 0.6365 & 0.6614 & 0.9623 & 0.5458 & 0.5545 & 0.9844 & 0.6273 & 0.3330 & 1.8836 & 0.5339 & 0.5427 & 0.9838 \\
\hline Shanghai & 1.0000 & 1.0000 & 1.0000 & 1.0000 & 1.0000 & 1.0000 & 1.0000 & 1.0000 & 1.0000 & 1.0000 & 1.0000 & 1.0000 \\
\hline Jiangsu & 1.0000 & 1.0000 & 1.0000 & 1.0000 & 1.0000 & 1.0000 & 0.8649 & 1.0000 & 0.8649 & 0.9777 & 1.0000 & 0.9777 \\
\hline Zhejiang & 1.0000 & 1.0000 & 1.0000 & 1.0000 & 1.0000 & 1.0000 & 0.8851 & 1.0000 & 0.8851 & 0.9706 & 0.9858 & 0.9846 \\
\hline Anhui & 0.5747 & 0.5826 & 0.9864 & 0.6270 & 0.6284 & 0.9978 & 0.6697 & 0.5325 & 1.2578 & 0.6941 & 0.7737 & 0.8971 \\
\hline Fujian & 1.0000 & 1.0000 & 1.0000 & 0.9703 & 1.0000 & 0.9703 & 0.9245 & 1.0000 & 0.9245 & 1.0000 & 1.0000 & 1.0000 \\
\hline Jiangxi & 0.6273 & 0.6362 & 0.9860 & 0.6949 & 0.7079 & 0.9816 & 0.6328 & 0.4159 & 1.5214 & 0.6792 & 0.6858 & 0.9903 \\
\hline Shandong & 0.9146 & 0.9557 & 0.9570 & 0.8354 & 0.8811 & 0.9482 & 0.8413 & 0.6606 & 1.2736 & 0.8334 & 1.0000 & 0.8334 \\
\hline Henan & 0.8397 & 0.8735 & 0.9613 & 0.7716 & 0.8480 & 0.9099 & 0.6985 & 1.0000 & 0.6985 & 0.7889 & 0.8331 & 0.9469 \\
\hline Hubei & 0.6488 & 0.6551 & 0.9903 & 0.6446 & 0.6453 & 0.9989 & 0.6772 & 0.3878 & 1.7463 & 0.6893 & 0.7804 & 0.8833 \\
\hline Hunan & 0.7448 & 0.7519 & 0.9906 & 0.7870 & 0.8162 & 0.9642 & 0.8182 & 0.5736 & 1.4264 & 0.9825 & 0.9958 & 0.9866 \\
\hline Guangdong & 1.0000 & 1.0000 & 1.0000 & 1.0000 & 1.0000 & 1.0000 & 1.0000 & 1.0000 & 1.0000 & 0.8865 & 1.0000 & 0.8865 \\
\hline Guangxi & 0.6175 & 0.6312 & 0.9784 & 0.6987 & 0.7013 & 0.9963 & 0.6369 & 0.3382 & 1.8833 & 0.6108 & 0.6232 & 0.9802 \\
\hline Hainan & 0.4667 & 0.6441 & 0.7246 & 0.5227 & 0.5597 & 0.9339 & 0.5534 & 1.0000 & 0.5534 & 0.6916 & 0.8765 & 0.7891 \\
\hline Chongqing & 0.6362 & 0.6492 & 0.9801 & 0.6709 & 0.6716 & 0.9990 & 0.6842 & 1.0000 & 0.6842 & 0.7824 & 0.7852 & 0.9965 \\
\hline Sichuan & 0.7032 & 0.7040 & 0.9988 & 0.7090 & 0.7503 & 0.9450 & 0.6597 & 1.0000 & 0.6597 & 0.6578 & 0.7130 & 0.9225 \\
\hline Guizhou & 0.6114 & 0.6497 & 0.9411 & 0.6493 & 0.6574 & 0.9877 & 0.6366 & 1.0000 & 0.6366 & 0.6373 & 0.6442 & 0.9893 \\
\hline Yunnan & 0.6252 & 0.6383 & 0.9795 & 0.6046 & 0.6081 & 0.9941 & 0.6184 & 1.0000 & 0.6184 & 0.6565 & 0.6616 & 0.9923 \\
\hline Tibet & 0.4687 & 1.0000 & 0.4687 & 0.8293 & 1.0000 & 0.8293 & 0.5016 & 1.0000 & 0.5016 & 0.5232 & 1.0000 & 0.5232 \\
\hline Shaanxi & 0.7435 & 0.7503 & 0.9910 & 1.0000 & 1.0000 & 1.0000 & 0.8634 & 1.0000 & 0.8634 & 0.8225 & 0.8257 & 0.9961 \\
\hline Gansu & 0.5666 & 0.6043 & 0.9376 & 0.5229 & 0.5330 & 0.9809 & 0.4643 & 0.3399 & 1.3659 & 0.4589 & 0.4817 & 0.9525 \\
\hline Qinghai & 0.7346 & 1.0000 & 0.7346 & 0.7857 & 0.8269 & 0.9502 & 0.6759 & 1.0000 & 0.6759 & 0.6914 & 1.0000 & 0.6914 \\
\hline Ningxia & 0.4713 & 0.5703 & 0.8265 & 0.6054 & 0.7352 & 0.8234 & 0.6549 & 1.0000 & 0.6549 & 0.6585 & 0.8105 & 0.8124 \\
\hline Xinjiang & 0.5172 & 0.5440 & 0.9508 & 0.4674 & 0.4747 & 0.9846 & 0.4990 & 0.5815 & 0.8581 & 0.4325 & 0.4401 & 0.9826 \\
\hline
\end{tabular}

From a time series evolutionary perspective, the number of provinces at the provincial scale reaching the production front did not increase significantly, and the technical efficiency did not improve significantly from 2008 to 2017. When considering spatial differences, Beijing, Shanghai, Jiangsu, Zhejiang, Guangdong, and other provinces were technically effective and the urban land use efficiency was relatively high. Most of the other provinces did not reach their production frontiers, and there was space for efficiency improvement. The proportion of provinces that reached the frontier of production in China is relatively low, and there is room for efficiency improvement in most provinces.

\subsection{Geospatial Analysis of Provincial Urban Land Use Efficiency}

\subsubsection{Spatial Correlation Analysis}

Using the spatial analysis tool GeoDa1.14 [52] the Global Moran's I indexes of ULUE in 31 provinces (municipalities, autonomous regions) in Chinese mainland of 2008, 2011, 2014, and 2017 were calculated. Table 4 shows the results of Moran's I index of ULUE in China. Except for 2011, the P-values of the evaluation units all passed the significance test at the level of 1\%. The index in 2011 passed the significance test at a level of $10 \%$. The indexes were all positive and the range was $[0.1,0.4]$, which indicates that the ULUE of provincial-level regions has significant spatial clustering characteristics, and there is a positive spatial correlation. Moran's I tends to increase year by year with time series, demonstrating that the spatial agglomeration degree of provincial ULUE increases year by year.

The Local Moran's I scatter plot (Figure 3) portrays the spatial aggregation types of provincial ULUE for each of the four time sections of 2008, 2001, 2014, and 2017. Among them, Beijing, Tianjin, Shanghai, Hebei, Jiangsu, Zhejiang, and Fujian are in high-high concentration areas, and Ningxia, Jiangxi, Hubei, Anhui, and Jilin are in low-high concentration areas. Heilongjiang, Guizhou, Yunnan, Sichuan, Gansu, and Xinjiang are in 
low-low concentration areas. The spatial aggregation types of 13 provinces changed during 2008-2017; for example, Chongqing shifted from low-low to high-low, Guangxi shifted from low-low to low-high, and Guangdong shifted from high-low to high-high.

Table 4. Global Moran's I and hypothesis tests of provincial urban land use efficiency in China.

\begin{tabular}{ccccc}
\hline & $\mathbf{2 0 0 8}$ & $\mathbf{2 0 1 1}$ & $\mathbf{2 0 1 4}$ & $\mathbf{2 0 1 7}$ \\
\hline Moran's I & 0.195 & 0.073 & 0.262 & 0.327 \\
$p$ value & 0.006 & 0.083 & 0.002 & 0.001 \\
Z scores & 2.9321 & 1.335 & 3.6201 & 4.4723 \\
\hline
\end{tabular}
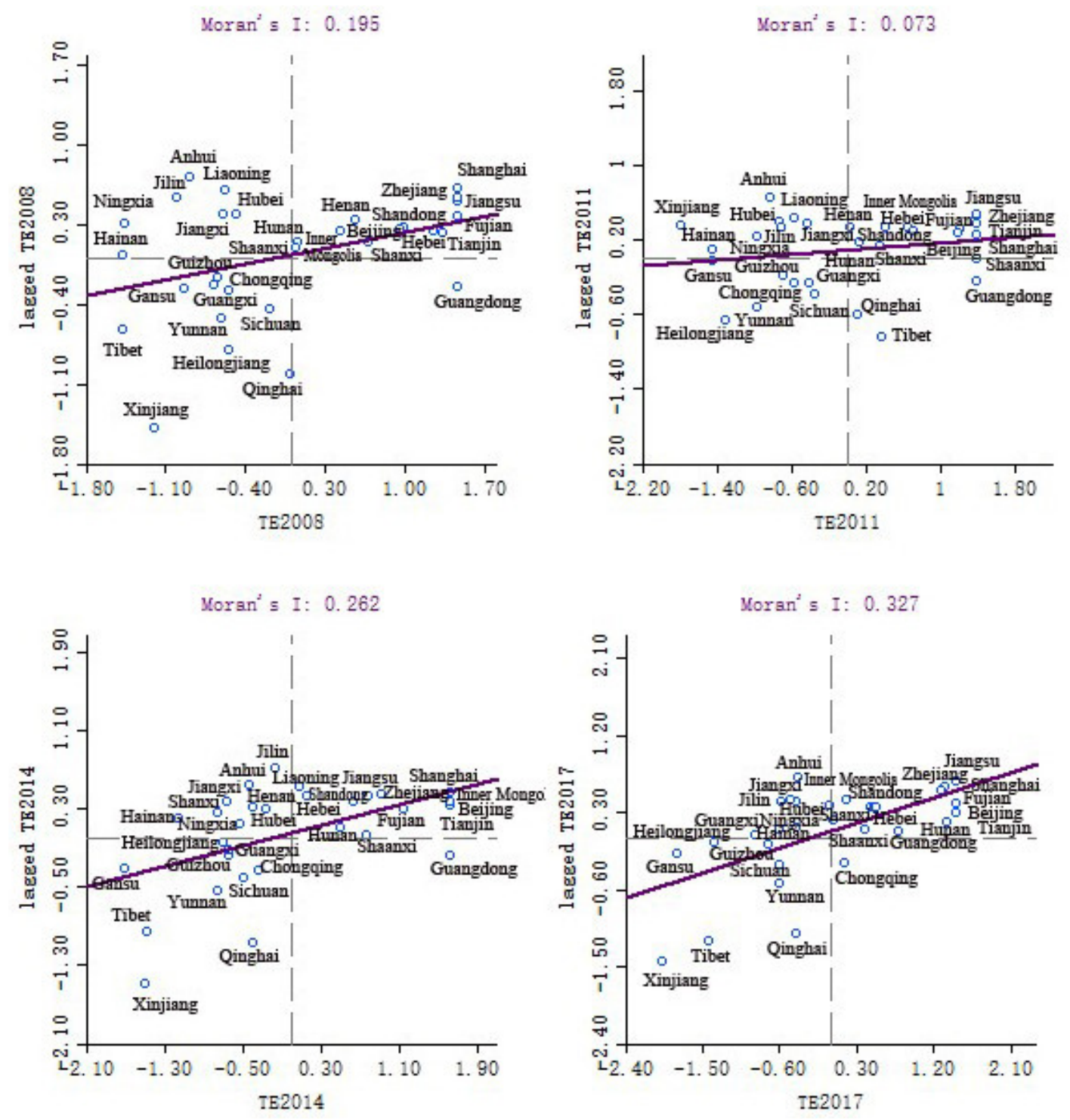

Figure 3. Local Moran 's I scatter plot of provincial urban land use efficiency in China.

\subsubsection{Spatial Feature Analysis}

Figure 4 shows the provincial ULUE from 2008 to 2017, visualized by ArcMap10.2. With time variations, the spatial pattern of ULUE changes at the provincial scale. Among them, some provincial regions are relatively stable, such as Beijing, Tianjin, Shanghai, Shandong, Jiangsu, Zhejiang, Fujian and Guangdong in the high-level group; Guizhou, Qinghai, Jiangxi, Sichuan, Chongqing, Guangxi, and Hubei in the mid-level group; and Xinjiang, Tibet, Shaanxi and Gansu the low-level group. There are changes in efficiency 
levels in some provinces. For example, Inner Mongolia shifted from the high-level group to medium-level group, there was a "low $\rightarrow$ high" transition in Jilin and a "medium $\rightarrow$ high" transition in Hunan.

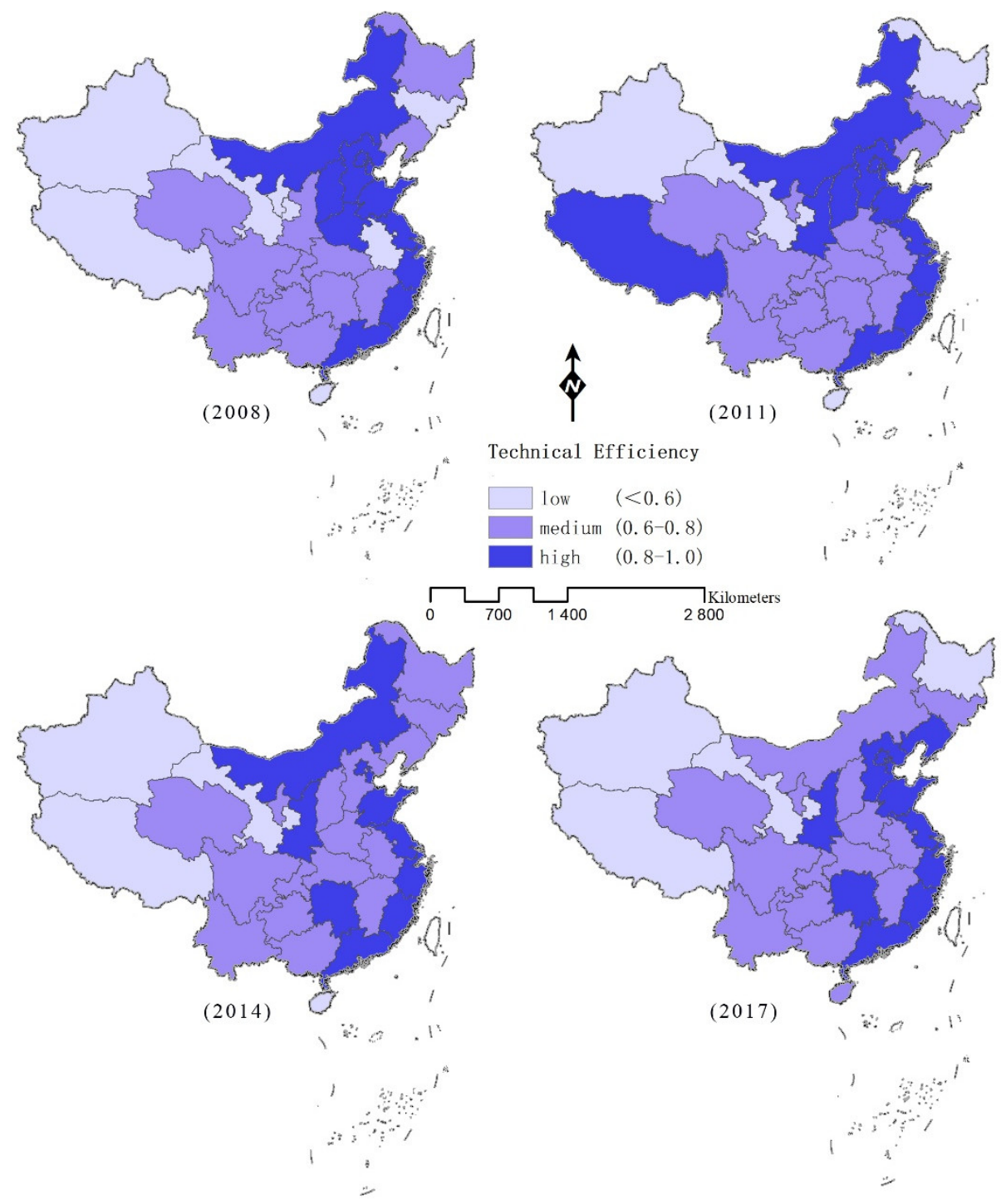

Figure 4. Spatial distribution of provincial urban land use efficiency in China.

\subsubsection{Gravity Center Analysis}

According to the technical efficiency values of the urban land in four sections in 2008, 2011, 2014, and 2017, the spatial gravity center migration model was adopted to obtain the coordinates of the technical efficiency gravity center from 2008 to 2017. Figure 5 visualizes the center of gravity migration (using ArcMap10.2). The visualization results indicate that the center of gravity of urban land efficiency at the provincial scale from 2008 to 2017 is located in Henan Province, China. During the study period, the gravity center of provincial ULUE moved $0.04^{\circ}$ to the east and $0.18^{\circ}$ to the south, indicating that the provincial urban land use in Southeast China was more efficient. The straight-line distance of gravity center migration was only $20.96 \mathrm{~km}$, which indicates that the gravity center is relatively stable. 


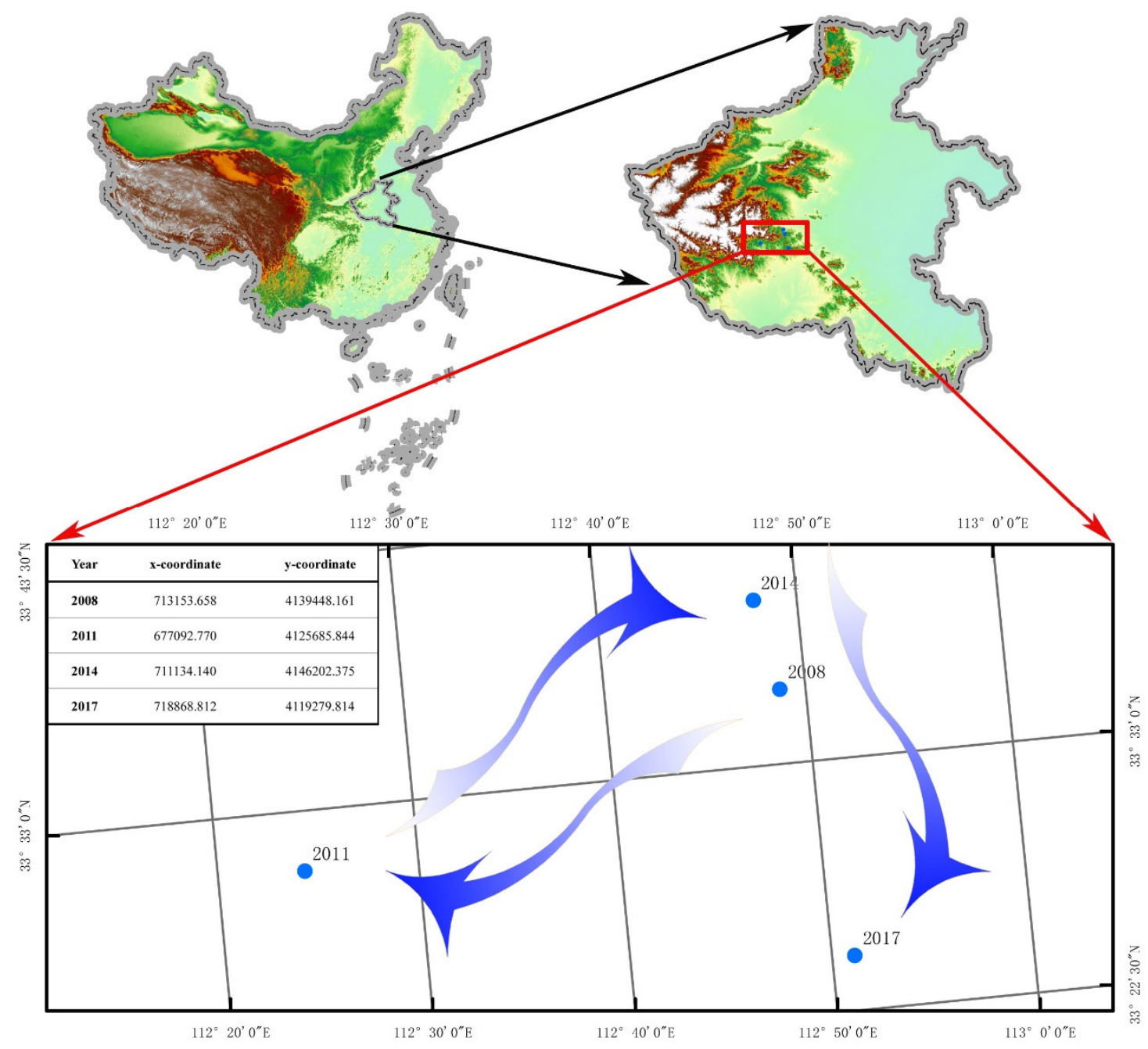

Figure 5. Gravity center migration of provincial ULUE in China from 2008 to 2017.

\section{Discussion}

The ULUE results include an assessment of the ecological development by decomposing the technical efficiency into pure technical efficiency and scale efficiency. Furthermore, it helped to identify the spatial patterns, spatial distributions and spatial transfers of ULUE and it led to the depiction of the spatial-temporal evolution of ULUE at the provincial scale in China. Hence, the employed methodology can identify practical problems when relying on ULUE and seeking practical solutions.

The proportion of provinces reaching the production frontier in China is relatively low, and there is room for improvement in ULUE in most provincial regions, which is closely related to the phased characteristics of China's urbanization. Over the past 20 years, China's urban land has shown a trend of rapid expansion. The excessive expansion of urban land will undoubtedly lead to some resource and environmental problems [53]. In particular, China's urbanization rate has exceeded $60 \%$, reaching the post-middle stage of urbanization, which shows the inefficient use or idleness of urban land [54], the disorderly spread of urban space [53], the land management mode of local governments seeking development by land [55], the long-term land hoarding phenomenon of some real estate developers driven by interests, and the low-cost investment attraction of some industrial land. These problems have affected the development of ULUE and need to be solved by improving ULUE. The promotion of ULUE is of great practical significance for alleviating the imbalance between the supply and demand of urban land resources, the sustainable use of land resources, the healthy development of urbanization and the realization of the 
United Nations Sustainable Development Goals (SDGs) [56]. Therefore, local governments should improve the land management system and policies, reduce the idle use and waste of urban land by improving the land trading market and standardizing the approval of construction projects, dynamically monitor and clean up inefficient land, activate the stock land resources in the city and improve the efficiency of resource utilization. Secondly, we should regulate the capital entry into the real estate market and reduce inefficient investment and disorderly competition in the real estate industry.

The spatial agglomeration of ULUE is increasing year by year, which shows that the spatial connection of urban land use is increasing. Therefore, in the process of land development and utilization, it is necessary to consider not only the impact of local economic and social factors, but also the spillover effect of land development and utilization in the neighborhood. First of all, in the process of land development and utilization, the inter-regional division of labor and cooperation, functional complementarity, and linkage development should be considered and a cross-regional cooperation mechanism should be constructed. For example, Chongqing can conduct joint planning with neighboring provinces such as Sichuan and Guizhou to avoid the repeated construction of industries and homogenized competition to improve ULUE. Secondly, according to the regional resource endowment conditions and ecological environment capacity, it can build a cross-regional industrial transfer mechanism to promote the adjustment and optimization of industrial layout. For example, the Yangtze River Economic Belt can reasonably position the function and industrial direction of its internal cities according to urban resources, environment and location, so as to realize the industrial integrated development of the Yangtze River Economic Belt.

ULUE is closely related to the economic level, location and development foundation [57]. Beijing, Jiangsu, Zhejiang and other regions have rapid economic and social development, a high level of economic and social development and relatively high land investment, so ULUE is at a high level. The central part of China is at a medium level, while the western part of China is at a relatively low level due to the limitations of location, resources, climate, landform and other factors. This is consistent with the conclusions of previous studies on urban land use efficiency in China [56]. Beijing, Jiangsu, Zhejiang and other provinces and cities should pay attention to further promoting the optimization of industrial structure and economic development, while radiating and driving the central and western regions of China to improve ULUE. The central and western regions of China will be the key regions of the promotion of ULUE; these regions can develop diversified land development models in combination with their own resources and environment to improve ULUE, which is also of great significance to promote the realization of the United Nations SDGs.

\section{Conclusions}

This study investigates the provincial ULUE in China from 2008 to 2017, based on the SBM-GPA model and considering the degree of green development. From a time series perspective, the efficiency at the provincial scale did not improve significantly from 2008 to 2017. From the perspective of spatial differences, the proportion of provincial regions that reached the production frontier is relatively low, and there is space for improvement in most provincial regions. The ULUE at the provincial scale has significant spatial clustering characteristics, and there is a positive spatial correlation, and the degree of spatial agglomeration tends to increase year by year. The gravity center of the provincial ULUE is located in Henan Province, which moved $20.96 \mathrm{~km}$ in the southeast during 2008-2017. It is relatively stable, with only a limited spatial variation.

Author Contributions: Conceptualization, X.C. and S.H.; methodology, X.C.; software, S.H.; validation, L.S. and C.L.; formal analysis, T.Z.; investigation, C.L. and L.S.; resources, L.S.; data curation, F.Z. and F.L.; writing - original draft preparation, S.H.; writing—review and editing, T.Z., C.L. and W.T.d.V.; visualization, X.C.; supervision, M.C.; project administration, X.C.; funding acquisition, X.C. All authors have read and agreed to the published version of the manuscript. 
Funding: China Postdoctoral Science Foundation: 2019M651885. Open Project of Key Laboratory of Ethnic Information E-commerce in Universities of Gansu Province (CN): 2020-2; the Fundamental Research Funds for the Central Universities, Zhongnan University of Economics and Law (CN): 202111023, 202111073, 202111076.

Institutional Review Board Statement: Not applicable.

Informed Consent Statement: Not applicable.

Data Availability Statement: All data generated or analyzed during this study are included in this published article.

Conflicts of Interest: The authors declare no conflict of interest.

\section{References}

1. Huang, J.; Xue, D. Study on temporal and spatial variation characteristics and influencing factors of land use efficiency in Xi'an, China. Sustainability 2019, 11, 6649. [CrossRef]

2. Zhang, L.; Zhang, L.; Xu, Y.; Zhou, P.; Yeh, C.-H. Evaluating urban land use efficiency with interacting criteria: An empirical study of cities in Jiangsu China. Land Use Policy 2020, 90, 104292. [CrossRef]

3. Zhu, X.; Zhang, P.; Wei, Y.; Li, Y.; Zhao, H. Measuring the efficiency and driving factors of urban land use based on the DEA method and the PLS-SEM model—a case study of 35 large and medium-sized cities in China. Sustain. Cities Soc. 2019, 50, 101646. [CrossRef]

4. Zhang, S. Land-Centered urban politics in transitional China-can they be explained by growth machine theory? Cities 2014, 41, 179-186. [CrossRef]

5. Cheng, X.; Li, N.; Mu, H.; Guo, Y.; Jiang, Y. Study on total-factor energy efficiency in three provinces of northeast China based on SBM model. Energy Procedia 2018, 152, 131-136. [CrossRef]

6. Chen, Y.; Chen, Z.; Xu, G.; Tian, Z. Built-up land efficiency in urban China: Insights from the General land use plan (2006-2020). Habitat Int. 2016, 51, 31-38. [CrossRef]

7. He, S.; Yu, S.; Li, G.; Zhang, J. Exploring the influence of urban form on land-use efficiency from a spatiotemporal heterogeneity perspective: Evidence from 336 Chinese cities. Land Use Policy 2020, 95, 104576. [CrossRef]

8. Bren d'Amour, C.; Reitsma, F.; Baiocchi, G.; Barthel, S.; Güneralp, B.; Erb, K.-H.; Haberl, H.; Creutzig, F.; Seto, K.C. Future urban land expansion and implications for global croplands. Proc. Natl. Acad. Sci. USA 2017, 114, 8939-8944. [CrossRef] [PubMed]

9. Wang, Y.; Song, G. The benefits evaluation method and application of urban land use. Geogr. Sin. 2006, 26, 743-748. (In Chinese)

10. Cui, X.; Fu, S.; Wei, Y. An integrated methodology in exploring the influential factors underlying the quality of land urbanization. J. Nonlinear Convex Anal. 2019, 20, 1065-1075.

11. Liu, Y. Introduction to land use and rural sustainability in China. Land Use Policy 2018, 74, 1-4. [CrossRef]

12. Zhu, X.; Li, Y.; Zhang, P.; Wei, Y.; Zheng, X.; Xie, L. Temporal-Spatial characteristics of urban land use efficiency of China's 35mega cities based on DEA: Decomposing technology and scale efficiency. Land Use Policy 2019, 88, 104083. [CrossRef]

13. Lü, G.; Batty, M.; Strobl, J.; Lin, H.; Zhu, A.-X.; Chen, M. Reflections and speculations on the progress in geographic information systems (GIS): A geographic perspective. Int. J. Geogr. Inf. Sci. 2019, 33, 346-367. [CrossRef]

14. Deng, J.; Desjardins, M.R.; Delmelle, E.M. An Interactive platform for the analysis of landscape patterns: A cloud-based parallel approach. Ann. GIS 2019, 25, 99-111. [CrossRef]

15. Chen, M.; Voinov, A.; Ames, D.P.; Kettner, A.J.; Goodall, J.L.; Jakeman, A.J.; Barton, M.C.; Harpham, Q.; Cuddy, S.M.; DeLuca, C.; et al. Position paper: Open web-distributed integrated geographic modelling and simulation to enable broader participation and applications. Earth Sci. Rev. 2020, 207, 103223. [CrossRef]

16. Rana, V.K.; Suryanarayana, T.M.V. GIS-Based multi criteria decision making method to identify potential runoff storage zones within watershed. Ann. GIS 2020, 26, 149-168. [CrossRef]

17. Jiao, L.; Xu, Z.; Xu, G.; Zhao, R.; Liu, J.; Wang, W. Assessment of urban land use efficiency in China: A perspective of scaling law. Habitat Int. 2020, 99, 102172. [CrossRef]

18. He, H.; Peng, C. The spatial-temporal evolution and the interactive effect between urban industrial structure transformation and land use efficiency. Geogr. Res. 2017, 36, 1271-1282. (In Chinese)

19. Lu, X.; Kuang, B.; Zhou, M. Spatial Inequality and influencing factors of utilization efficiency of urban construction land. China Popul. Resour. Environ. 2016, 26, 45-52. (In Chinese)

20. Masini, E.; Tomao, A.; Barbati, A.; Corona, P.; Serra, P.; Salvati, L. Urban growth, land-use efficiency and local socioeconomic context: A comparative analysis of 417 metropolitan regions in Europe. Environ. Manag. 2019, 63, 322-337. [CrossRef] [PubMed]

21. Fetzel, T.; Niedertscheider, M.; Haberl, H.; Krausmann, F.; Erb, K.-H. Patterns and changes of land use and land-use efficiency in Africa 1980-2005: An analysis based on the human appropriation of net primary production framework. Reg. Environ. Chang. 2016, 16, 1507-1520. [CrossRef]

22. Huang, H.; Peng, X. Urban Land Use Efficiency changes and improvement strategies from a decoupling perspective in Nanchang city. Resour. Sci. 2016, 38, 493-500. (In Chinese) 
23. Zitti, M.; Ferrara, C.; Perini, L.; Carlucci, M.; Salvati, L. Long-Term urban growth and land use efficiency in southern Europe: Implications for sustainable land management. Sustainability 2015, 7, 3359-3385. [CrossRef]

24. Cui, X.; Yang, S.; Zhang, G.; Liang, B.; Li, F. An exploration of a synthetic construction land use quality evaluation based on economic-social-ecological coupling perspective: A case study in major Chinese cities. IJERPH 2020, 17, 3663. [CrossRef]

25. Ke, X.; Yang, B.; Liu, S.; Ma, C. Optimization of interregional built-up land allocation based on differences of land use efficiency: A case study of Wuhan metropolitan. Resour. Environ. Yangtze Basin 2014, 23, 1502-1509. (In Chinese)

26. Zhao, W.; Luo, Y.; Wang, L. Influencing factors for the using efficiency of china's construction land: Analysis based on the provincial panel data in 2003-2012. Urban Probl. 2016, 2, 4-13. (In Chinese)

27. Jin, G.; Deng, X.; Zhao, X.; Guo, B.; Yang, J. Spatio-Temporal patterns of urban land use efficiency in the yangtze river economic zone during 2005-2014. Sci. Geogr. Sin. 2018, 73, 1242-1252. (In Chinese)

28. Yue, L.; Li, W.; Economics, S.O.; University, L. Typical urban land use efficiency in china under environmental constraints based on ddf-global malmquist-luenberger index modeling. Resour. Sci. 2017, 39, 597-607. (In Chinese)

29. Li, Y.; Shu, B.; Wu, Q. Urban land use efficency in China: Spatial and temporal characteristics, regional difference and influence factors. Econ. Geogr. 2014, 34, 133-139. (In Chinese)

30. Choi, Y.; Wang, N. The Economic efficiency of urban land use with a sequential slack-based model in Korea. Sustainability 2017, 9 , 79. [CrossRef]

31. Herzig, A.; Nguyen, T.T.; Ausseil, A.-G.E.; Maharjan, G.R.; Dymond, J.R.; Arnhold, S.; Koellner, T.; Rutledge, D.; Tenhunen, J. Assessing resource-use efficiency of land use. Environ. Model. Softw. 2018, 107, 34-49. [CrossRef]

32. Cui, X. The spatial pattern and spillover effect of land-use efficiency. Econ. Manag. 2014, 28, 19-25. (In Chinese)

33. Yang, K.; Wen, Q.; Zhong, T. Assessment of urban land use efficiency in the yangtze river economic belt. Resour. Sci. 2018, 40, 2048-2059. (In Chinese)

34. Zhang, R.T.; Jiao, H.F. Urban land use efficiency pattern evolution and driving mechanism in the yangtze river economic belt. Resour. Environ. Yangtze Basin 2015, 24, 387-394. (In Chinese)

35. Li, C.; Miao, M. Urban land use efficiency measurement of city group in middle reaches of yangtze river:Reality mechanism and spatiotemporal diversities. China Popul. Resour. Environ. 2017, 27, 157-164. (In Chinese)

36. Lee, B.S. Land use regulations and efficiency of seoul's economy. Int. J. Urban Sci. 1998, 2, 48-72. [CrossRef]

37. Tone, K. A Slacks-Based measure of efficiency in data envelopment analysis. Eur. J. Oper. Res. 2001, 130, 498-509. [CrossRef]

38. Charnes, A.; Cooper, W.W.; Rhodes, E. Measuring the efficiency of decision making units. Eur. J. Oper. Res. 1978, 2, 429-444. [CrossRef]

39. Yang, H.; Hu, Y.; Wang, Q. Evaluation of land use efficiency in three major urban agglomerations of China in 2001-2012. Sci. Geogr. Sin. 2015, 35, 1095-1100. (In Chinese)

40. Lu, X.; Chen, D.; Kuang, B.; Zhang, C.; Cheng, C. Is high-tech zone a policy trap or a growth drive? Insights from the perspective of urban land use efficiency. Land Use Policy 2020, 95, 104583. [CrossRef]

41. Yang, K.; Zhong, T.; Zhang, Y.; Wen, Q. Total factor productivity of urban land use in China. Growth Chang. 2020, 51, 1784-1803. [CrossRef]

42. Yang, Q.; Duan, X.; Ye, L.; Zhang, W. Efficiency evaluation of city land utilization in the yangtze river delta using a SBMundesirable model. Resour. Sci. 2014, 36, 712-721. (In Chinese)

43. Shan, L.; Jiang, Y.H.; Liu, C.C.; Wang, Y.F.; Zhang, G.H.; Cui, X.F.; Li, F. Exploring the multi-dimensional coordination relationship between population urbanization and land urbanization based on the MDCE model: A case study of the Yangtze River economic belt, China. PLoS ONE 2021, 16, e0253898. [CrossRef]

44. Gao, X.; Zhang, A.; Sun, Z. How regional economic integration influence on urban land use efficiency? A case study of Wuhan metropolitan area, China. Land Use Policy 2020, 90, 104329. [CrossRef]

45. Moran, P.A.P. Notes on continuous stochastic phenomena. Biometrika 1950, 37, 17-23. [CrossRef] [PubMed]

46. Bao, H.; Shan, L.; Wang, Y.; Jiang, Y.; Lee, C.; Cui, X. How does local real estate investment influence neighborhood PM2.5 concentrations? A spatial econometric analysis. Land 2021, 10, 518. [CrossRef]

47. Chen, X. Spatiotemporal mapping and multiple driving forces identifying of PM2.5 variation and its joint management strategies across China. J. Clean. Prod. 2020, 250, 119534. [CrossRef]

48. Boots, B.N.; Gaile, G.L.; Willmott, C.J. Spatial statistics and models. Econ. Geogr. 1985, 61, 199. [CrossRef]

49. Zhang, J.; Zhang, K.; Zhao, F. Research on the regional spatial effects of green development and environmental governance in China based on a spatial autocorrelation model. Struct. Chang. Econ. Dyn. 2020, 55, 1-11. [CrossRef]

50. Schuurman, N.; Bérubé, M.; Crooks, V.A. Measuring potential spatial access to primary health care physicians using a modified gravity model. Can. Geogr. 2010, 5, 29-45. [CrossRef]

51. Chai, J.; Wang, Z.; Yang, J.; Zhang, L. Analysis for spatial-temporal changes of grain production and farmland resource: Evidence from Hubei province, central China. J. Clean. Prod. 2019, 207, 474-482. [CrossRef]

52. Anselin, L.; Li, X. Operational local join count statistics for cluster detection. J. Geogr. Syst. 2019, 21, 189-210. [CrossRef]

53. Tang, Y.; Wang, K.; Ji, X.; Xu, H.; Xiao, Y. Assessment and spatial-temporal evolution analysis of urban land use efficiency under green development orientation: Case of the Yangtze river delta urban agglomerations. Land 2021, 10, 715. [CrossRef]

54. Liu, Y.; Fang, F.; Li, Y. Key issues of land use in China and implications for policy making. Land Use Policy 2014, 40, 6-12. [CrossRef] 
55. Wu, R.; Li, Z.; Wang, S. The varying driving forces of urban land expansion in China: Insights from a spatial-temporal analysis. Sci. Total Environ. 2021, 766, 142591. [CrossRef]

56. Liu, S.; Xiao, W.; Li, L.; Ye, Y.; Song, X. Urban land use efficiency and improvement potential in China: A stochastic frontier analysis. Land Use Policy 2020, 99, 105046. [CrossRef]

57. Wang, A.; Lin, W.; Liu, B.; Wang, H.; Xu, H. Does smart city construction improve the green utilization efficiency of urban land? Land 2021, 10, 657. [CrossRef] 